\title{
Preliminary study: voluntary food intake in dogs during tryptophan supplementation
}

\author{
Víctor Fragua, Gemma González-Ortiz, Cecilia Villaverde*, Marta Hervera, Valentina Maria Mariotti, \\ Xavier Manteca and María Dolores Baucells \\ Animal Nutrition, Management and Welfare Research Group, Department of Animal and Food Science, Universitat \\ Autònoma de Barcelona, Campus UAB, 08193 Cerdanyola, Spain
}

(Received 18 October 2010 - Revised 17 December 2010 - Accepted 11 January 2011)

\section{Abstract}

Tryptophan, a precursor of important molecules such as serotonin, melatonin and niacin, is an essential amino acid for dogs. In pigs, tryptophan supplementation has been shown to induce a significant increase in food intake. The aim of the present study was to assess whether long-term tryptophan supplementation increases voluntary food intake in dogs and to observe whether this was accompanied by a change in serum ghrelin. In the present study, sixteen adult Beagle dogs were used, with four male and four female dogs fed diets supplemented with tryptophan $(1 \mathrm{~g} / \mathrm{dog}$ per $\mathrm{d}$ ) during $81 \mathrm{~d}$ (Trp) and four male and four female dogs that were not supplemented (control). A voluntary food intake test was performed during $5 \mathrm{~d}$ following the supplementation period. The Trp group tended to show a higher food intake during the voluntary food intake test (58.0 (SE 5.37) v. 77.5 (sE 3.65) g/kg metabolic weight per d; $P=0.074)$. No significant differences were found for serum ghrelin concentrations.

\section{Key words: Tryptophan: Food intake: Ghrelin: Dogs}

Tryptophan is an essential amino acid for monogastric animals. It is a metabolic precursor of neurotransmitters, such as serotonin and melatonin, and also of niacin (vitamin $\left.\mathrm{B}_{3}\right)^{(1)}$.

Alterations in the serotonin metabolic pathway have been implicated in the pathophysiology of several behavioural disorders such as aggression, depression and anxiety. A relationship between low concentrations of 5-hydroxytryptohan in the cerebrospinal fluid and aggression ${ }^{(2-4)}$ has been suggested. DeNapoli et al. ${ }^{(5)}$ showed that a low-protein diet supplemented with tryptophan might help in managing canine aggression problems. However, Bosch et al. ${ }^{(6)}$ showed that there was no effect of tryptophan supplementation $(5.70 \mathrm{~g} / 100 \mathrm{~g} \mathrm{DM})$ on the behaviour of anxious dogs. Therefore, the influence of dietary tryptophan intake on the behaviour of pathologically anxious or chronically stressed dogs remains to be established.

Besides its proposed effect on behaviour, some studies in growing pigs have shown that tryptophan supplementation can result in a significant increase in food intake ${ }^{(7-9)}$. One of the proposed mechanisms of action is through the influence on mRNA expression and secretion of hormones in the stomach, intestine and other organs, which may then regulate food intake by cooperation with the nervous system ${ }^{(10)}$.
Ghrelin is one of the gut peptide hormones ${ }^{(11-14)}$, which has been shown to be affected by long-term administration of tryptophan in growing pigs ${ }^{(15)}$. In the present study, tryptophan supplementation resulted in elevations of both feed intake and serum ghrelin, thus suggesting that tryptophan may have an effect on feed intake via this hormone.

Since long-term tryptophan supplementation in dogs has been proposed by DeNapoli et $a l^{(5)}$ as a helpful therapy to treat patients with behavioural problems, it is of interest to examine possible side effects of this treatment on food intake and also to assess whether there is any change in serum ghrelin in response the treatment. Thus, the aim of the present study was to assess whether long-term tryptophan supplementation increases voluntary food intake in dogs and to observe whether this was accompanied by a change in serum ghrelin.

\section{Materials and methods}

\section{Experimental animals}

Institutional guidelines for the care and use of animals were followed, and all the experimental procedures involving animals were approved by the Internal Animal Care and

Abbreviation: Trp, tryptophan.

*Corresponding author: C. Villaverde, email cecilia.villaverde@gmail.com 
Use Committee of the Universitat Autònoma de Barcelona (Cerdanyola, Spain). An animal behaviour specialist regularly assessed the health and welfare of the dogs. The dogs were placed individually in temperature-controlled kennels at the Veterinary School (Universitat Autònoma de Barcelona), with an elevated platform for them to rest. Fresh water was available at all times. All dogs underwent a physical examination by a veterinarian at the beginning and at the end of the study to ensure they were in good health.

A total of sixteen Beagle dogs, between 1 and 7 years of age, were randomly distributed into two experimental groups, resulting in eight animals (four males and four females) per treatment. The control group (body weight 13.1 (SE $1 \cdot 13 \mathrm{~kg}$ ) was fed the experimental diet throughout the study. The treatment group (Trp; body weight 14.5 ( $\mathrm{se} 0.68) \mathrm{kg}$ ) was fed the same experimental diet as the control and was supplemented orally with tryptophan (Indukern S.A., Barcelona, Spain) in a capsule $(1 \mathrm{~g} / \mathrm{dog}$ per $\mathrm{d})$. At the time of the meal, the control group did not receive a capsule. Animals were fed once a day according to their respective body weight $\left.(110 \times \text { (body weight })^{0.75}\right)$. Food intake was controlled daily. Animals were weighed monthly during the experimental period.

\section{Experimental period and diets}

The experimental period was $121 \mathrm{~d}$ long. From days 0 to 23 , the dogs were transitioned from their regular maintenance food to the experimental food $(1646 \mathrm{~kJ} / 100 \mathrm{~g}$, with an energy distribution of $12 \%$ protein, $37 \%$ fat and $51 \%$ carbohydrates on a metabolisable energy basis, and with a tryptophan concentration of $0 \cdot 176 \mathrm{~g} / 100 \mathrm{~g}$ as is). The protein level in the experimental food is above the National Research Council's recommended allowance ${ }^{(1)}$. The supplementation with tryptophan was conducted from days 23 to 103.

\section{Ghrelin analysis}

Blood samples were obtained in order to determine total ghrelin (Total ghrelin RIA kit; Linco Research, St Charles, MO, USA) in the morning of days 23 and 96 at 08.00 hours just before feeding. These samples were obtained by jugular venepuncture, and serum was obtained after centrifugation. The samples were stored at $-20^{\circ} \mathrm{C}$ until analysis.

\section{Voluntary food intake test}

A voluntary food intake test was performed from days 99 to 103. The test was performed as follows: $600 \mathrm{~g}$ of a maintenance diet $(1646 \mathrm{~kJ} / 100 \mathrm{~g}$, energy distribution: 18\% protein; $38 \%$ fat; $44 \%$ carbohydrates on a metabolisable energy basis) was supplied during $20 \mathrm{~min}$ twice per day (at 09.00 and 18.30 hours). After $20 \mathrm{~min}$, the remaining food was collected and the refusal weight was recorded. No additional food was provided to the animals. The first day was considered as an adaptation day and was thus not included in the statistical analysis.

\section{Statistical analysis}

Serum ghrelin concentrations and voluntary food intake data were analysed by ANOVA with a commercial statistical program (SAS ${ }^{\circledR}$ version 9.1; SAS Institute Inc., 2002, Cary, NC, USA). The principal effects were the treatment group, the day and the interaction between group and day. A $P$ value of 0.05 was considered significant.

\section{Results}

\section{Effects of tryptophan supplementation on voluntary food intake}

The average total food intake during the voluntary food intake test was 376.3 (sE 32.58) g/dog per d for the control group and 569.6 (SE 31.07) g/dog per $\mathrm{d}$ for the Trp group $(P=0 \cdot 017)$. The average food intake is expressed $\mathrm{kg}$ metabolic weight (body weight elevated to 0.75$)$ and tended to be higher in the Trp group $v$. the control group $(58.0$ ( $\mathrm{SE} 5.37) \mathrm{g} / \mathrm{kg}$ metabolic weight per $\mathrm{d}$ for the control group and 77.5 (SE 3.65 ) g/kg metabolic weight per $\mathrm{d}$ for the Trp group, $P=0.074)$. There were no differences in food intake among the $4 \mathrm{~d}$ of the test $(P=0 \cdot 419)$. The interaction between day and experimental group was not significant either $(P=0.363)$. Table 1 shows the average total food intake per $\mathrm{kg}$ metabolic weight for each day of the voluntary food intake test.

\section{Effects of tryptophan supplementation on total serum ghrelin concentration}

The average total serum ghrelin concentration on day 23, at the beginning of tryptophan supplementation, was 3516.5 (sE 872.35$) \mathrm{pg} / \mathrm{ml}$ for the control group and 3363.6 (sE $496 \cdot 23) \mathrm{pg} / \mathrm{ml}$ for the Trp group $(P=0.998)$. Total serum ghrelin concentration on day 96 , before the voluntary food intake test and after $81 \mathrm{~d}$ of tryptophan supplementation, was 1877.9 (SE 272.80$) \mathrm{pg} / \mathrm{ml}$ for the control group and 2724.2 (SE 774.48$) \mathrm{pg} / \mathrm{ml}$ for the supplemented group, as shown in Fig. $1(P=0.759)$. There was a significant effect of time, with a decrease in serum ghrelin after $81 \mathrm{~d}$ in both groups $(P=0.009)$.

Table 1. Food intake for each day of the voluntary food intake test of dogs fed the experimental diet $(n 8)$ and dogs fed the experimental diet supplemented with tryptophan $(n 8)$

(Mean values with their standard errors)

\begin{tabular}{|c|c|c|c|c|c|}
\hline & \multicolumn{2}{|c|}{$\begin{array}{l}\text { Control group } \\
\text { (g consumed/ } \\
\text { kg MW) }\end{array}$} & \multicolumn{2}{|c|}{$\begin{array}{l}\text { Supplemented } \\
\text { group (g consu- } \\
\text { med/kg MW) }\end{array}$} & \multirow[b]{2}{*}{$P$} \\
\hline & Mean & SE & Mean & SE & \\
\hline Day 2 & $58 \cdot 1$ & 9.25 & 79.5 & 7.04 & 0.094 \\
\hline Day 3 & $69 \cdot 8$ & $13 \cdot 10$ & 76.5 & 6.54 & 0.597 \\
\hline Day 4 & 53.9 & $10 \cdot 11$ & 76.6 & 7.63 & 0.077 \\
\hline Day 5 & $50 \cdot 1$ & 11.01 & 77.4 & 9.18 & 0.035 \\
\hline
\end{tabular}

MW, metabolic weight. 


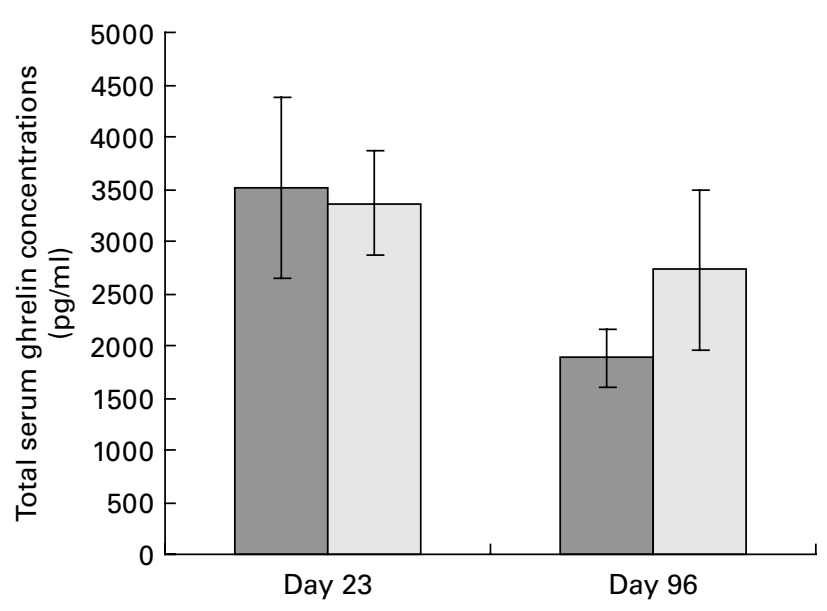

Fig. 1. Effects of tryptophan (Trp) supplementation on total ghrelin levels. Total ghrelin level was measured. Values are means, with their standard errors represented by vertical bars $(n 8)$. Mean values were not significantly different for group $(P=0.660)$. Mean values were significantly different for day $(P<0.01)$. Control $(\square)$, Trp $(\square)$, supplemented group (pg/ml).

\section{Discussion}

The present study aimed to investigate the effect of tryptophan supplementation on voluntary food intake in dogs and to observe whether this effect, if observed, was related to serum ghrelin concentrations. The voluntary food intake test in the present study suggests that tryptophan supplementation in dogs eating a low-protein diet, at the doses used, tends to result in a higher food intake compared with dogs eating a low-protein diet alone. That response has been observed in weanling pigs ${ }^{(15)}$, where dietary tryptophan supplementation induced a significant increase in food intake in these species. In the present study, the supplementation period of tryptophan was $21 \mathrm{~d}$. In pigs, the long-term administration of tryptophan induced higher plasma ghrelin levels. In the same study with pigs, they found increased serum ghrelin in the supplemented group. However, we did not observe this relationship in the present study.

It is important to mention that the present study is part of a larger project whose main goal is to study the effect of tryptophan supplementation on different biochemistry markers related to canine aggression. The availability of dietary tryptophan to the brain is largely dependent on the composition of the ingested diet, in particular the ratio of tryptophan to other large neutral amino acids ${ }^{(16)}$. The concentration of tryptophan in the central nervous system can be increased either by increasing plasma tryptophan or by lowering plasma concentrations of large neutral amino acids ${ }^{(17)}$. For this reason, the experimental diet in the present trial was lower in protein compared with standard canine maintenance diets. This could have affected the present results regarding serum ghrelin, since plasma ghrelin levels can be dependent on diet composition, since one study in human subjects has found that a low-protein, high-fat diet resulted in decreased plasma ghrelin concentration ${ }^{(18)}$. As mentioned, the protein concentration of the experimental diet was lower than the protein concentration of the dogs' regular maintenance diet $(0 \cdot 81 / 100$ v. $1.56 \mathrm{~g} / 100 \mathrm{~kJ}$ metabolisable energy). The diet switch from a standard maintenance diet to a low-protein diet during the experimental period may explain the drop in serum ghrelin concentration from days 23 to 96 . However, the decrease in ghrelin levels was higher in the control group than in the supplemented group.

In conclusion, the present study shows that long-term tryptophan supplementation at the doses used $(1 \mathrm{~g} / \mathrm{dog}$ per d) tended to increase voluntary food intake in dogs, which was not correlated with increases in total serum ghrelin. The effect of longer or shorter supplementation times and different doses is at this point unknown, and so is the effect of tryptophan supplementation on other hormones involved in food intake and satiety regulation (such as leptin and cholecystokinin).

\section{Acknowledgements}

We thank Tura Ferrer (Centre de Biotecnologia Animal i Teràpia Gènica) for her collaboration in total ghrelin determination. We would like to thank Indukern S.A. and the Ajinomoto Group for their kind donation of tryptophan. We also thank the Servei de Granges i Camps Experimentals de la Universitat Autònoma de Barcelona for their service and assistance during the experiment. The present study was funded by internal departmental funds (Animal and Food Science). There are no conflicts of interest between the authors. The contribution of each author to the study was as follows: V. F. and M. D. B. participated in the study design and in the writing of the manuscript. G. G.-O., V. M. M. and X. M. participated in the study design. C. V. and M. H. participated in the writing of the manuscript.

\section{References}

1. National Research Council (NRC) (2006) Nutrient Requirements of Dogs and Cats. Washington, DC: National Academy Press.

2. Edwards DH \& Kravitz EA (1997) Serotonin, social status and aggression. Curr Opin Neurobiol 7, 812-819.

3. Lesch KP \& Merschdorf U (2000) Impulsivity, aggression, and serotonin: a molecular psychobiological perspective. Behav Sci Law 18, 581-604.

4. Reisner IR, Mann JJ, Stanley M, et al. (1996) Comparison of cerebrospinal fluid monoamine metabolite levels in dominant-aggressive and non-aggressive dogs. Brain Res 714, 57-64

5. DeNapoli JS, Dodman NH, Shuster L, et al. (2000) Effect of dietary protein content and tryptophan supplementation on dominance aggression, territorial aggression, and hyperactivity in dogs. J Am Vet Med Assoc 217, 504-508.

6. Bosch G, Beerda B, Beynen AC, et al. (2009) Dietary tryptophan supplementation in privately owned mildly anxious dogs. Appl Anim Behav Sci 121, 197-205.

7. Eder K, Peganova S \& Kluge H (2001) Studies on the tryptophan requirement of piglets. Arch Tierernahr 55, 281-297.

8. Ettle T \& Roth FX (2004) Specific dietary selection for tryptophan by the piglet. J Anim Sci 82, 1115-1121.

9. Henry Y, Seve B, Colleaux Y, et al. (1992) Interactive effects of dietary levels of tryptophan and protein on voluntary feed intake and growth performance in pigs, in relation to plasma 
free amino acids and hypothalamic serotonin. J Anim Sci 70, 1873-1887.

10. Meister B (2000) Control of food intake via leptin receptors in the hypothalamus. Vitam Horm 59, 265-304.

11. Geary N (2004) Endocrine controls of eating: CCK, leptin, and ghrelin. Physiol Behav 81, 719-733.

12. Inui A (2001) Ghrelin: an orexigenic and somatotrophic signal from the stomach. Nat Rev Neurosci 2, 551-560.

13. Knerr I, Groschl M, Rascher W, et al. (2003) Endocrine effects of food intake: insulin, ghrelin, and leptin responses to a single bolus of essential amino acids in humans. Ann Nutr Metab 47, 312-318.

14. Ukkola O (2003) Endocrinological activities of ghrelin: new insights. Eur J Intern Med 14, 351-356.
15. Zhang H, Yin J, Li D, et al. (2007) Tryptophan enhances ghrelin expression and secretion associated with increased food intake and weight gain in weanling pigs. Domest Anim Endocrinol 33, 47-61.

16. Spring B, Chiodo J \& Bowen DJ (1987) Carbohydrates, tryptophan, and behavior: a methodological review. Psychol Bull 102, 234-256.

17. Bosch G, Beerda B, Hendriks WH, et al. (2007) Impact of nutrition on canine behaviour: current status and possible mechanisms. Nutr Res Rev 20, 180-194.

18. Erdmann J, Lippl F \& Schusdziarra V (2003) Differential effect of protein and fat on plasma ghrelin levels in man. Regul Pept 116, 101-107. 